\title{
Estrutura da Pastagem e Padrões de Desfolhação em Capim-Mombaça em Diferentes Alturas do Dossel Forrageiro
}

\author{
Ana Luisa Palhano², Paulo César de Faccio Carvalho 3 , João Ricardo Dittrich ${ }^{4}$, Aníbal de \\ Moraes $^{4}$, Marsânia Zap Barreto ${ }^{5}$, Melony Caroline Ferreira dos Santos ${ }^{5}$
}

RESUMO - Com o objetivo de avaliar o padrão de desfolhação em pastagens de capim-mombaça (Panicum maximum, Jacq.), novilhas leiteiras da raça HPB foram submetidas, em testes de pastejo, a cinco alturas de dossel (60, 80, 100, 120 e 140 cm), em um delineamento completamente casualizado, com duas repetições. Caracterizou-se a estrutura do dossel por meio de: altura; oferta de forragem, massa de forragem e de lâminas foliares; densidade volumétrica da forragem, de colmos mais bainhas e de lâminas foliares; densidade populacional de perfilhos; número e comprimento de lâminas foliares expandidas e em expansão. Com o aumento da altura do dossel, observou-se redução linear ( $\hat{Y}=0,369606+0,001555 \mathrm{x}, \mathrm{R}^{2}=0,5560, \mathrm{P}=0,008$ ) na probabilidade de desfolhação das plantas, como resultado da maior massa de forragem. Com o incremento em altura do dossel, notadamente à altura de $85 \mathrm{~cm}$, os animais passaram a ingerir maior proporção de lâminas foliares expandidas à medida que as mesmas apresentaram-se mais acessíveis, apesar da maior preferência por lâminas foliares em expansão. A intensidade de desfolhação das folhas expandidas diminuiu linearmente $\left(\hat{Y}=80,866791-0,370979 x, R^{2}=0,6076\right.$, $\mathrm{P}=0,004)$, refletindo o aumento em seu comprimento $\left(\hat{Y}=-104,311106+2,877570 \mathrm{x}-0,012035 \mathrm{x}^{2}, \mathrm{R}^{2}=0,9271, \mathrm{P}=0,002\right)$ e também a maior resistência à apreensão, imposta pela idade das folhas. Com o aumento em altura do dossel, o padrão de desfolhação foi alterado, de maneira que os animais passaram a executar um pastejo mais periférico nas touceiras e com acesso reduzido às folhas em expansão, de melhor valor nutritivo.

Palavras-chave: densidade volumétrica, Panicum maximum, seleção de dietas, seletividade, tamanho da folha

\section{Sward Structure and Defoliation Patterns in Mombaçagrass According to Different Canopy Heights}

ABSTRACT - To evaluate the pattern of defoliation in a Mombaça (Panicum maximum) grass pasture, experimental paddocks were grazed by Holstein heifers to maintain canopy height of: 60, 80, 100, 120 and $140 \mathrm{~cm}$ height. The experimental design was completely randomized, with two replications. The assessed sward structures were: canopy height; herbage and leaf lamina mass; canopy, sheath plus stems and leaves bulk density; tiller density and number and length of fully-expanded and emerging leaves. Linear decrease in plant defoliation probability ( $\hat{Y}=0.369606+0.001555 \mathrm{x}, \mathrm{R}^{2}=0.5560, \mathrm{P}=0.008$ ) was observed as pasture height increased, as a reflection of increasing canopy herbage mass. Ingestion of fully expanded leaves increased with canopy height, mainly for the $85 \mathrm{~cm}$ canopy, in spite of the animal preference for emerging leaves. The intensity of defoliation of fully expanded leaves decreased linearly $(\hat{\mathrm{Y}}=80.866791$ $\left.-0.370979 \mathrm{x}, \mathrm{R}^{2}=0.6076, \mathrm{P}=0.004\right)$, reflecting their increased length $\left(\hat{\mathrm{Y}}=-104.311106+2.877570 \mathrm{x}-0.012035 \mathrm{x}^{2}, \mathrm{R}^{2}=0.9271\right.$, $\mathrm{P}=0.002$ ) and their greater resistance to apprehension by the animal, as well. The increase in canopy heights changed defoliation pattern of the animals, as the animals began to graze around the plants, due to the restricted access to the younger leaves, of greater nutritive value.

Key Words: volumetric density, Panicum maximum, diet selection, selectivity, leaf size

\section{Introdução}

O consumo de forragem e, portanto, de nutrientes é um aspecto determinante do desempenho animal e pode ser afetado por fatores relacionados à planta forrageira (Prache \& Peyraud, 2001) e ao animal (Cangiano et al., 2002). A estrutura da pastagem pode ser descrita sob os planos vertical e horizontal, sendo seu detalhamento minucioso primordial para o entendimento das relações entre as plantas forrageiras e os animais, pois, em condições de pastejo, o animal a reconhece e, dentro da variabilidade disponível, efetua suas escolhas alimentares, por meio da desfolhação. A desfolhação pode ser definida como a remoção de material vegetal, sendo caracterizada pela intensidade, freqüência e época de ocorrência.

\footnotetext{
${ }^{1}$ Dados parciais da tese de Doutorado da primeira autora apresentada à UFPR.

2 Profa. Dra. FIES: Rua Tobias de Macedo Jr, 333 e UTP: Rua Comendador Franco, 1860, Curitiba, PR (a.luisa@pop.com.br)

3 Prof. Dr. UFRGS: Rua Bento Gonçalves, 7712, Porto Alegre, RS (paulocfc@ ufrgs.br). Bolsista do CNPq.

4 Prof.Dr.UFPR: Rua dos Funcionários, 1540, Curitiba, PR (dittrich@ufpr.br; anibalm@ufpr.br).

5 Dicentes, curso de Zootecnia/FIES Rua: Tobias de Macedo Jr, 333 Curitiba, PR (barretoszoo@hotmail.com, melony@ig.com.br).
} 
A freqüência com que um mesmo perfilho é pastejado é definida como o intervalo entre duas desfolhações sucessivas, que corresponde à probabilidade diária de cada órgão vegetal ser desfolhado (Lemaire \& Chapman, 1996) e sofre interferência significativa da densidade animal (Wade, 1991), cujo aumento pode induzir maior número de perfilhos pastejados a cada dia (Hodgson, 1990).

A probabilidade de desfolhação de folhas individuais pode também ser afetada pela idade das folhas, de modo que as jovens têm maior probabilidade de serem pastejadas (Lemaire \& Agnusdei, 1999) por estarem situadas nos estratos superiores do dossel (Hodgson, 1990) e orientadas em posição mais vertical (Pontes, 2001), quando comparadas às folhas mais velhas. É importante ressaltar que essas observações são influenciadas pelo porte relativo entre a espécie forrageira em questão e os animais em pastejo.

A oferta de forragem, diretamente relacionada à densidade de animais, apresenta papel central na probabilidade de desfolhação de cada componente da pastagem, uma vez que, quando lhes é permitido, os animais utilizam sua habilidade seletiva para maximizarem a qualidade de sua dieta. Essas escolhas por parte do animal poderão ser diretamente afetadas por características relacionadas à facilidade de apreensão da forragem, um indicador para o animal do grau de facilidade da ação do bocado (Carvalho et al., 1999). Essas características englobam vários aspectos estruturais do dossel, como acessibilidade e densidade volumétrica da forragem, fibrosidade das folhas, disposição espacial dos órgãos vegetais preferidos, presença de barreiras à desfolhação, como bainhas e colmos, e teor de matéria seca.

A intensidade de desfolhação pode ser definida como a diferença entre o comprimento da fração removida pelo pastejo e o da lâmina foliar antes da desfolhação (Lemaire \& Agnusdei, 1999), observando-se que, também nesse aspecto, a taxa de lotação tem efeito marcante. As características físicas da forragem podem também alterar a proporção de material foliar removido, uma vez que afeta o esforço despendido pelos animais no processo de apreensão (Illius et al., 1995).

Diante dessas considerações, o objetivo deste estudo foi verificar como o padrão de desfolhação do capim-mombaça pode ser afetado por estruturas variáveis do dossel.

\section{Material e Métodos}

Como animais experimentais, foram utilizadas cinco novilhas da raça Holandês Preto e Branco, com peso médio de $152 \mathrm{~kg}$, sendo os resultados de cada avaliação obtidos a partir da média de cinco animais em pastejo.

Os tratamentos foram conduzidos durante o período de 12/02/02 a 14/04/02 e consistiram de cinco alturas de capim-mombaça (Panicum maximum Jacq.), correspondentes a $60,80,100,120$ e $140 \mathrm{~cm}$ e duas repetições. As alturas foram estabelecidas após dois rebaixamentos à mesma altura para todos os tratamentos, o primeiro em dezembro e o segundo em janeiro, ambos seguidos por adubações nitrogenadas em cobertura, nas dosagens de 100 e $50 \mathrm{~kg}$ de $\mathrm{N} \mathrm{ha}^{-1}$, respectivamente. A partir desse momento, as plantas cresceram livremente, até atingirem as alturas propostas para os tratamentos. Cada unidade experimental (piquete) possuía $540 \mathrm{~m}^{2}$.

Em cada dia de avaliação, foram efetuados os procedimentos de caracterização da estrutura do dossel e os testes de pastejo.

Previamente à entrada dos animais nos piquetes, mediu-se a altura do dossel, para aferição dos tratamentos propostos, utilizando-se um sward stick, um tipo de régua graduada, desenvolvida conforme método proposto por Barthram (1985). As medições foram realizadas em 75 pontos por piquete, permitindo-se variação máxima de $5 \%$ entre a altura medida e aquela especificada para cada tratamento.

Para quantificação da massa de forragem, foram coletadas cinco amostras da biomassa vegetal aérea por unidade experimental, estratificadas a $20 \mathrm{~cm}$ do nível do solo, utilizando-se de um equipamento projetado para delimitar sucessivos estratos do dossel por meio do deslocamento de um quadrado de ferro, preso por ganchos a cada $20 \mathrm{~cm}$, denominado estratificador. As amostras de forragem correspondentes a cada estrato do dossel foram pesadas, separadas em lâminas foliares, colmos mais bainhas e material senescente e, em seguida, colocadas em estufa de circulação forçada a $65^{\circ} \mathrm{C}$ até peso constante, para obtenção da massa de cada componente, expressa em kg de MS.ha ${ }^{-1}$. A massa de forragem, de colmos mais bainhas e de lâminas foliares foi determinada a partir da soma dos estratos em cada uma das cinco amostras.

A relação lâminas foliares/lâminas foliares mais colmos mais bainhas foi determinada a partir dos 
valores obtidos para essas frações conforme descrito anteriormente, sendo a mesma adimensional.

Os resultados obtidos para a massa de forragem, de lâminas foliares e de colmos mais bainhas foram utilizados para o cálculo das respectivas densidades volumétricas, sendo os valores expressos em $\mathrm{kg}$ de $\mathrm{MS} \mathrm{m}^{-3}$.

A densidade populacional de perfilhos foi determinada a partir de contagem direta do número de perfilhos presentes em uma área de $0,5625 \mathrm{~m}^{2}(0,75 \times 0,75 \mathrm{~m})$, delimitada por um quadrado de ferro, lançado cinco vezes de forma aleatória em cada repetição.

Apesar dos períodos de avaliação terem ocorrido tardiamente na estação de crescimento, menos de 5\% das plantas apresentaram início de florescimento, o que poderia ter alterado a relação lâminas foliares/ colmos + bainhas.

Para quantificação do número e comprimento de lâminas foliares expandidas e em expansão e do padrão de desfolhação da pastagem pelos animais em pastejo, foram utilizados 100 perfilhos marcados em cada repetição, para avaliação dos parâmetros probabilidade de desfolhação, índices de seletividade passiva e ativa e intensidade de desfolhação. Foram consideradas folhas expandidas aquelas que já tinham sua lígula exposta.

A probabilidade de desfolhação de cada folha referiu-se à relação entre o número total de folhas consumidas e o número total de folhas. Os índices de seletividade passiva e ativa foram calculados conforme apresentado na Tabela 1. A variável intensidade de desfolhação de lâminas foliares expressou o comprimento da fração foliar removida em relação ao comprimento inicial das mesmas antes do pastejo.

As avaliações das folhas foram efetuadas nos perfilhos antes e após os testes de pastejo, quando foram medidos os comprimentos das lâminas de todas as folhas; as expandidas foram medidas desde a lígula até seu ápice e aquelas em expansão, desde a lígula da penúltima folha expandida até o ápice da folha em expansão.
A oferta de forragem nos diferentes tratamentos foi calculada por meio da relação entre a massa de forragem disponível e a carga animal presente nos piquetes durante o período das avaliações, sendo expressa em porcentagem do peso vivo, ou seja, em kg de MS para cada 100 kg de peso vivo. O mesmo procedimento foi conduzido para determinação da oferta de lâminas foliares.

Foram realizados 10 testes de pastejo (cinco alturas de dossel e duas repetições) durante o período de 12/02/02 a 14/04/02, cada um com duas sessões de 45 minutos de pastejo, simulando a entrada dos animais nos piquetes, em um sistema de lotação rotacionada. Para os testes, realizados no período da manhã após jejum de sólidos e líquidos por 6 horas, foram utilizados cinco animais experimentais. Ao final de cada teste, os animais eram liberados nas áreas adicionais, também formadas com o capim-mombaça.

O delineamento experimental utilizado foi o completamente casualizado, com cinco tratamentos e duas repetições, sendo os dados obtidos para as variáveis relacionadas aos padrões de desfolhação, analisados por meio de regressões polinomiais de primeiro e segundo graus, utilizando-se o aplicativo STATGRAPHICS. As comparações de médias, realizadas apenas para os parâmetros estruturais do dossel, entre os tratamentos, foram feitas pelo teste Duncan, a 5\% de significância.

\section{Resultados e Discussão}

As alturas efetivas do dossel foram diferentes entre os tratamentos, como se observa na Tabela 2 .

Os dados reportados por Martinichen (2002) substanciam a premissa de que, nestas condições (Tabela 3), não houve oferta limitante de forragem aos animais, uma vez que, nas condições estabelecidas pela autora, foram ofertados, em média, 52 kg de MS

Tabela 1 - Índices de seletividade passiva e ativa de lâminas foliares em capim-mombaça

Table 1 - Passive and active selective indexes of leaves in mombaçagrass

Índice de seletividade passiva Passive selectivity index Fully-emerged leaves consumed
Lâminas foliares em expansão consumidas
Emerging leaves consumed

Lâminas foliares em expansão consumidas
Emerging leaves consumed

Lâminas foliares expandidas consumidas
Índice de seletividade ativa Active selectivity index
Lâminas foliares em expansão consumidas/
Lâminas foliares em expansão totais Emerging leaves consumed /Total emerging leaves

Lâminas foliares expandidas consumidas/ Lâminas foliares expandidas totais Fully-emerged leaves consumed/Total fully-emerged leaves 
de forragem.animal ${ }^{-1}$.dia ${ }^{-1}$ e $30 \mathrm{~kg}$ de MS de lâminas foliares.animal ${ }^{-1}$.dia ${ }^{-1}$, o que resultou em produção média de $15 \mathrm{~kg}$ de leite.animal ${ }^{-1} \cdot \mathrm{dia}^{-1}$, para animais manejados exclusivamente em pastagem de capimmombaça.

Houve aumento da massa de forragem e de lâminas foliares, reflexo do incremento observado na altura do dossel (Tabela 4).

Quanto à distribuição vertical de lâminas foliares, colmos mais bainhas e material senescente ao longo de estratos contínuos de $20 \mathrm{~cm}$ do dossel (Figura 1), observou-se, no estrato basal, à altura de $20 \mathrm{~cm}$ do dossel, proporção reduzida de lâminas foliares e elevada de material senescente, condição resultante da baixa luminosidade presente e do hábito de crescimento da planta.

A fração colmos mais bainhas concentrou-se no estrato médio inferior em todas as alturas testadas, de maneira que as lâminas foliares estiveram presentes em uma proporção superior a $85 \%$ da massa de forragem existente na metade superior do dossel (Tabela 5). Nessas condições, a ingestão de forragem pelos animais pode não ter sido limitada, uma vez que os animais tendem a selecionar as folhas dos estratos superiores do dossel (Chacon \& Stobbs, 1976; Hodgson, 1990; Prache et al.,1998), concentrando os bocados no horizonte acima do pseudocolmo (Hodgson, 1990), condição permitida pela curta duração dos testes de pastejo. Dessa maneira, a estrutura de dossel disponível e apresentada aos animais seria capaz de proporcionar uma dieta quase que exclusiva de lâminas foliares durante os testes de pastejo.

Conforme reportado por Carvalho (1997), a presença da fração colmos mais bainhas é considerada, por alguns autores, uma limitação física à ingestão de forragem pelos animais, uma vez que pode reduzir a profundidade do bocado, o que não ocorre em todas as situações. Flores et al. (1993), ao trabalharem com Paspalum dilatatum, Poiret, não verificaram limitação às dimensões do bocado imposta pelo pseudocolmo.

Tabela 2 - Alturas efetivas do dossel de capim-mombaça, no início e término dos testes de pastejo Table 2 - Effective sward heights of mombaçagrass in the beginning and final of the grazing tests

\begin{tabular}{|c|c|c|c|c|c|}
\hline \multicolumn{5}{|c|}{$\begin{array}{l}\text { Altura de entrada }(\mathrm{cm}) \\
\text { Initial sward height }(\mathrm{cm})\end{array}$} & \multirow[t]{2}{*}{ CV (\%) } \\
\hline 60 & 80 & 100 & 120 & 140 & \\
\hline \multirow[t]{2}{*}{$58,9 e^{*}$} & 79,3d & $96,5 c$ & $116,6 \mathrm{~b}$ & $133,0 \mathrm{a}$ & 2,5 \\
\hline & & $\begin{array}{l}\text { de saíd } \\
\text { vard heic }\end{array}$ & & & \\
\hline 60 & 80 & 100 & 120 & 140 & \\
\hline $42,7 \mathrm{e}$ & $59,6 \mathrm{~d}$ & $96,4 c$ & $104,9 b$ & $114,1 \mathrm{a}$ & 4,8 \\
\hline
\end{tabular}

* Médias seguidas da mesma letra não diferem significativamente pelo teste Duncan a 5\%.

* Means followed by the same letter do not differ by Duncan test at $5 \%$.

Tabela 3 - Oferta de forragem, conforme a altura do dossel em capim-mombaça Table 3 - Herbage allowance according to sward height in mombaçagrass

\begin{tabular}{|c|c|c|c|c|c|}
\hline \multicolumn{5}{|c|}{$\begin{array}{l}\text { Altura do dossel }(\mathrm{cm}) \\
\text { Sward height }(\mathrm{cm})\end{array}$} & \\
\hline 60 & 80 & 100 & 120 & 140 & \\
\hline \multirow{3}{*}{$59,4 b^{*}$} & \multicolumn{4}{|c|}{$\begin{array}{l}\text { Volume de forragem em oferta (kg de MS.100 kg de } \mathrm{PV}^{-1} \text { ) } \\
\left.\text { Herbage volume allowance ( } \mathrm{kg} D \mathrm{M} .100 \mathrm{~kg} \mathrm{BW^{-1 }}\right)\end{array}$} & \\
\hline & $66,8 \mathrm{ab}$ & $76,6 \mathrm{ab}$ & $89,0 \mathrm{ab}$ & $104,4^{\mathrm{a}}$ & 14,4 \\
\hline & \multicolumn{4}{|c|}{$\begin{array}{l}\text { Oferta de lâminas foliares (kg de MS.100 kg de } \mathrm{PV}^{-1} \text { ) } \\
\text { Leaf blade allowance ( } \mathrm{kg} D \mathrm{DM} .100 \mathrm{~kg} \mathrm{BW}^{-1} \text { ) }\end{array}$} & \\
\hline $9,9 c^{*}$ & 21,1bc & $28,8 \mathrm{~b}$ & $35,7 a b$ & $46,5 \mathrm{a}$ & 20,3 \\
\hline
\end{tabular}

* Médias seguidas da mesma letra, na mesma linha, não diferem significativamente pelo teste Duncan a 5\%.

* Means followed by the same letter, in the same row, do not differ by Duncan test at $5 \%$. 
(a)

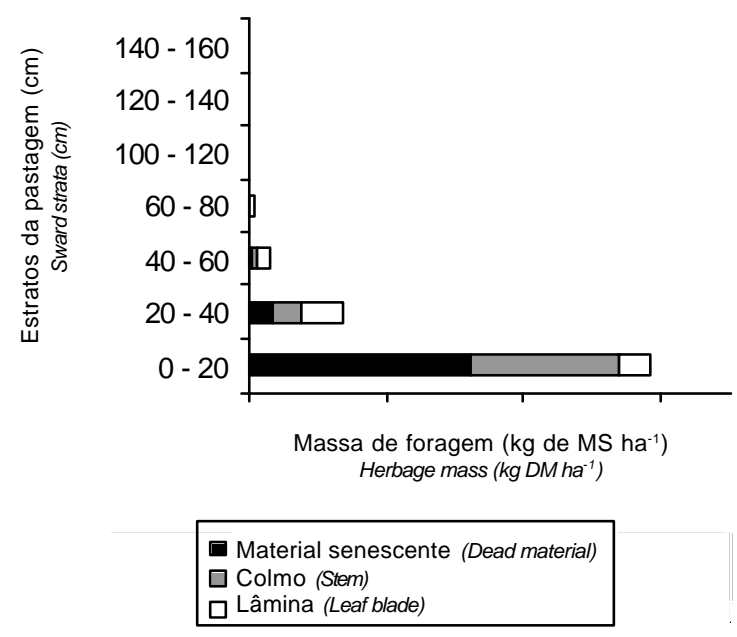

(c)

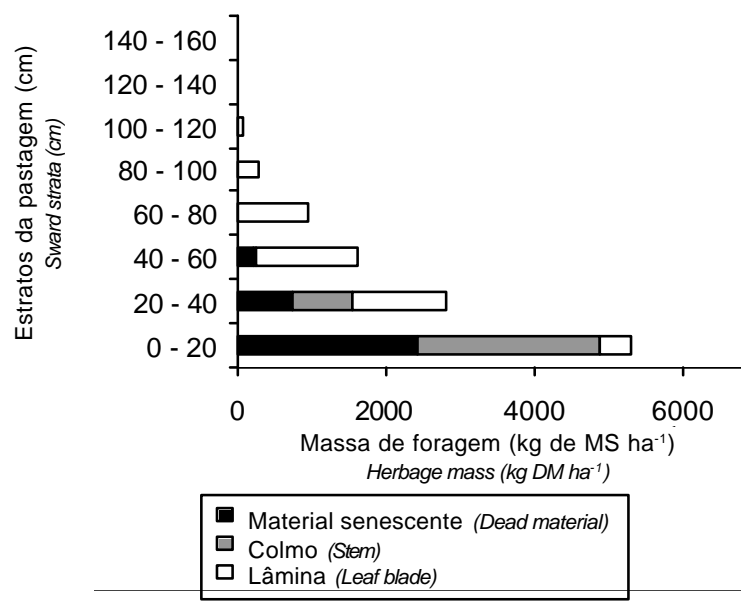

(b)

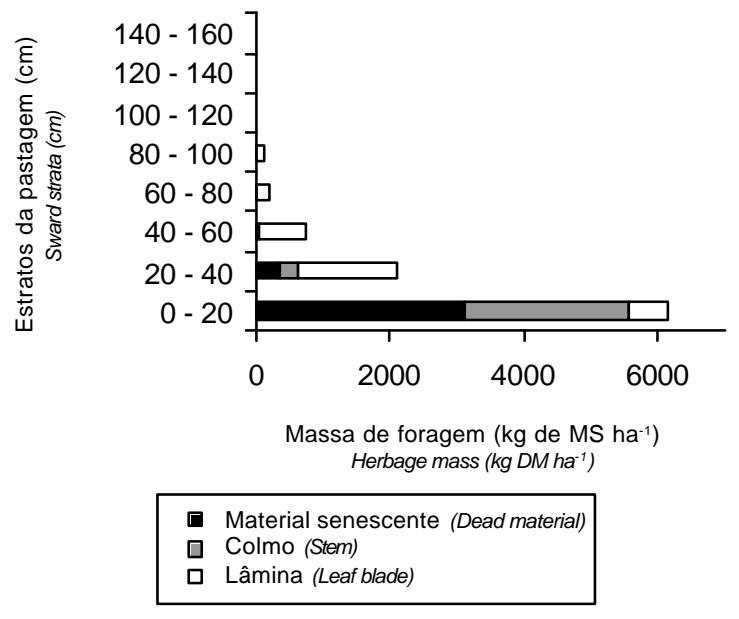

(d)

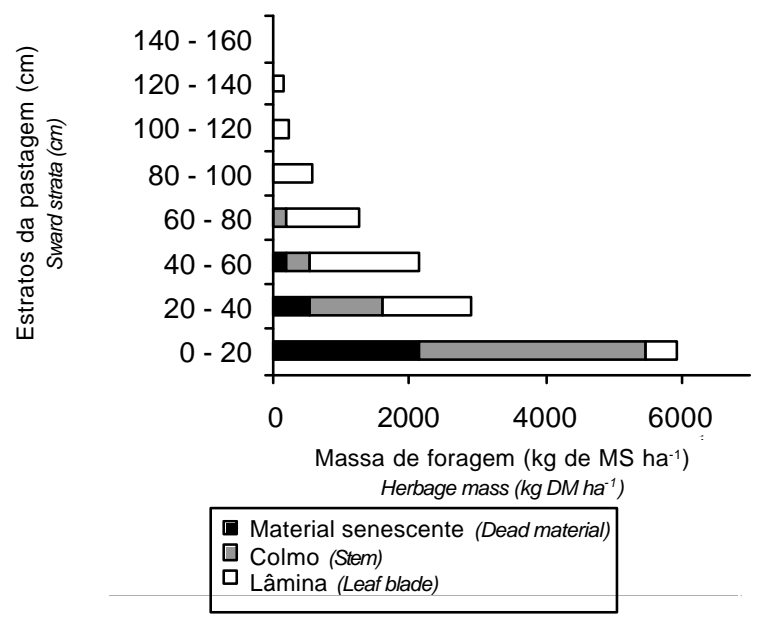

(e)

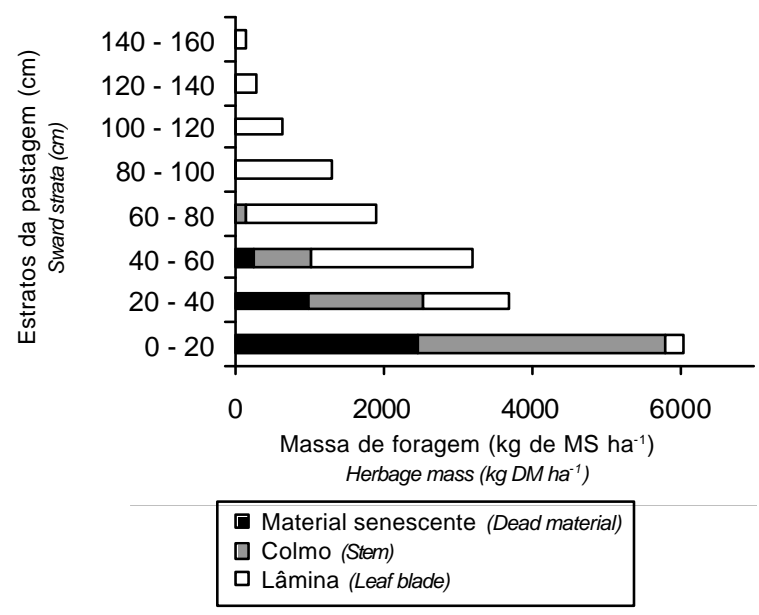

Figura 1 - Distribuição da massa de forragem referente às alturas de 60 (a), 80 (b), 100 (c), 120 (d) e 140 (e) ao longo do perfil do dossel forrageiro do capim-mombaça.

Figure 1 - Herbage mass distribution along sward profile according to heights of 60(a), 80(b), 100(c), 120(d) and 140(e) in mombaçagrass. 
Tabela 4 - Massas de forragem e de lâminas foliares, referentes às alturas de 60, 80, 100,120 e $140 \mathrm{~cm}$ do dossel em capim-mombaça

Table 4 - Herbage and leaf blade mass of sward heights of 60, 80,100, 120 and $140 \mathrm{~cm}$ in mombaçagrass

\begin{tabular}{|c|c|c|c|c|c|}
\hline \multicolumn{5}{|c|}{$\begin{array}{l}\text { Altura do dossel }(\mathrm{cm}) \\
\text { Sward height }(\mathrm{cm})\end{array}$} & \multirow[t]{2}{*}{$\mathrm{CV}(\%)$} \\
\hline 60 & 80 & 100 & 120 & 140 & \\
\hline \multicolumn{6}{|c|}{$\begin{array}{c}\text { Massa de forragem }\left(\mathrm{kg} \text { de MS.ha- } \mathrm{ha}^{-1}\right) \\
\text { Herbage mass }\left(\mathrm{kg} \mathrm{DM} \cdot \mathrm{ha}^{-1}\right)\end{array}$} \\
\hline $7569 c$ & $9130 \mathrm{bc}$ & $11063 b c$ & $13126 a b$ & $17247 \mathrm{a}$ & 13,2 \\
\hline \multicolumn{6}{|c|}{$\begin{array}{l}\text { Massa de lâminas foliares }\left(\mathrm{kg} \text { de MS.ha }{ }^{-1}\right) \\
\text { Leaf blade mass }\left(\mathrm{kg} D M . \mathrm{ha}^{-1}\right)\end{array}$} \\
\hline $1399 d^{*}$ & $2911 \mathrm{~cd}$ & $4114 b c$ & $5328 b$ & $7678 \mathrm{a}$ & 17,1 \\
\hline
\end{tabular}

* Médias seguidas da mesma letra, na mesma linha, não diferem significativamente pelo teste Duncan a $5 \%$.

* Means followed by the same letter do not differ by Duncan test at $5 \%$.

Tabela 5 - Relação massa de lâminas foliares/massa de lâminas foliares mais colmos mais bainhas, em estratos de $20 \mathrm{~cm}$ do dossel de capim-mombaça

Table 5 - Leaf blade mass/leaf blade mass + stem + sheath ratio, in $20 \mathrm{~cm}$ strata in mombaçagrass

\begin{tabular}{|c|c|c|c|c|c|}
\hline \multirow[t]{2}{*}{$\begin{array}{l}\text { Estratos do dossel }(\mathrm{cm}) \\
\text { Sward strata }\end{array}$} & \multicolumn{5}{|c|}{$\begin{array}{l}\text { Altura do dossel }(\mathrm{cm}) \\
\text { Sward height }(\mathrm{cm})\end{array}$} \\
\hline & 60 & 80 & 100 & 120 & 140 \\
\hline $120-140$ & & & & & 1,00 \\
\hline $100-120$ & & & & 1,00 & 1,00 \\
\hline $80-100$ & & & 1,00 & 1,00 & 0,97 \\
\hline $60-80$ & & 1,00 & 1,00 & 0,85 & 0,94 \\
\hline $40-60$ & 0,74 & 0,96 & 0,97 & 0,83 & 0,73 \\
\hline $20-40$ & 0,59 & 0,85 & 0,61 & 0,55 & 0,43 \\
\hline $0-20$ & 0,17 & 0,20 & 0,15 & 0,12 & 0,07 \\
\hline Média do perfil & $0,50 a^{*}$ & $0,75 b$ & $0,75 b$ & $0,73 b$ & $0,73 b$ \\
\hline Profile average & & & & & \\
\hline
\end{tabular}

* Médias seguidas da mesma letra não diferem significativamente pelo teste Duncan a 5\%.

* Means followed by the same letter do not differ by Duncan test at $5 \%$.

De acordo com Illius et al. (1995), o maior dispêndio de energia pelos animais durante o pastejo decorre da mastigação da forragem e não de sua remoção.

Por fim, Griffiths et al. (2003) verificaram que o pseudocolmo é um fator parcial de regulação da profundidade do bocado, uma vez que a relação custo:benefício, relacionada à procura por bocados, pode também ser influenciada pela idade do pseudocolmo, pelo contraste entre os estratos do dossel e pela altura do mesmo.

Os valores de densidade volumétrica da forragem e de colmos mais bainhas não variaram com o aumento da altura do dossel (Tabelas 6 e 7). Esse fato devese, provavelmente, a um efeito de diluição da massa de forragem produzida ao longo dos estratos nas maiores alturas do dossel. Quanto às lâminas foliares, houve aumento em densidade até a altura de $80 \mathrm{~cm}$ (Tabela 8).
Não houve variação em densidade populacional de perfilhos, com valores de 254 a 314 perfilhos por metro quadrado (Tabela 9), o que deve ter sido provocado pela escala temporal do experimento, que não permitiu a expressão da Lei da Compensação Tamanho/Densidade (Sbrissia \& Da Silva., 2001) e pelo fato de as áreas, no período pré-experimental, terem sido rebaixadas à mesma altura para todos os tratamentos. Os dados obtidos corroboram aqueles reportados por Uebele (2002) e Santos (1997), que, trabalhando com o capim-mombaça, não observaram efeito da intensidade e da freqüência de desfolhação sobre o número de perfilhos. Martinichen (2002) também não verificou variação na população de perfilhos de capim-mombaça submetido a duas alturas de pastejo, registrando valores de 320 a 326 perfilhos por metro quadrado. 
Tabela 6 - Densidade volumétrica de forragem em capim-mombaça ( $\mathrm{kg}$ de $\mathrm{MS} \mathrm{m}^{-3}$ ), conforme a altura do dossel Table 6 - Herbage volumetric density in mombaçagrass $\left(\mathrm{kg} \mathrm{DM} \mathrm{m}^{-3}\right)$ according to sward heigths

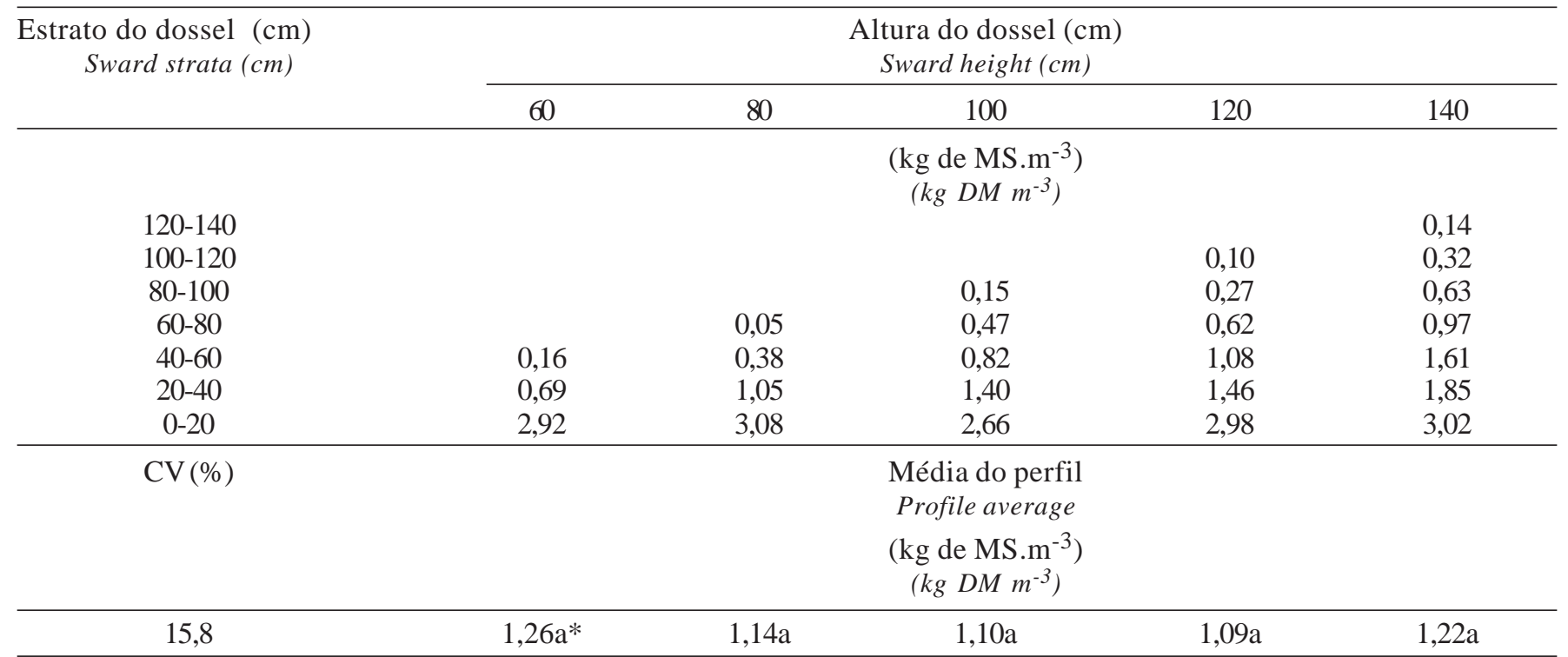

* Médias seguidas da mesma letra não diferem significativamente pelo teste Duncan a $5 \%$.

* Means followed by the same letter do not differ by Duncan test at 5\%.

Tabela 7 - Densidade volumétrica de colmos mais bainhas em capim-mombaça (kg de $\mathrm{MS}^{-3}$ ), conforme a altura do dossel

Table 7 - Stem + sheath volumetric density in mombaçagrass ( $\mathrm{kg} \mathrm{DM}^{-3}$ ) according to sward heights

\begin{tabular}{|c|c|c|c|c|c|}
\hline \multirow[t]{2}{*}{$\begin{array}{l}\text { Estrato do dossel }(\mathrm{cm}) \\
\text { Sward strata }(\mathrm{cm})\end{array}$} & \multicolumn{5}{|c|}{$\begin{array}{l}\text { Altura do dossel }(\mathrm{cm}) \\
\text { Sward height }(\mathrm{cm})\end{array}$} \\
\hline & 60 & 80 & 100 & 120 & 140 \\
\hline & & & $\begin{array}{l}\text { le } M S \\
D M n\end{array}$ & & \\
\hline $120-140$ & & & & & 0 \\
\hline $100-120$ & & & & 0 & 0 \\
\hline $80-100$ & & & 0 & 0 & 0 \\
\hline $60-80$ & & 0 & 0 & 0,09 & 0,05 \\
\hline $40-60$ & 0,04 & 0,02 & 0,02 & 0,16 & 0,40 \\
\hline $20-40$ & 0,22 & 0,13 & 0,40 & 0,54 & 0,77 \\
\hline $0-20$ & 1,08 & 1,21 & 1,23 & 1,68 & 1,66 \\
\hline \multirow[t]{2}{*}{$\mathrm{CV}(\%)$} & & & $\begin{array}{l}\text { ia do } \mathrm{f} \\
\text { ile ave }\end{array}$ & & \\
\hline & & & $\begin{array}{l}\text { le MS } \\
D M n\end{array}$ & & \\
\hline 25,2 & $0,45 a^{*}$ & $0,34 \mathrm{a}$ & $0,33 \mathrm{a}$ & $0,41 \mathrm{a}$ & $0,41 \mathrm{a}$ \\
\hline
\end{tabular}

* Médias seguidas da mesma letra não diferem significativamente pelo teste Duncan a 5\%.

* Means followed by the same letter do not differ by Duncan test at $5 \%$.

Quanto ao número total de folhas registrado nos perfilhos marcados, o menor valor foi observado para a altura de $60 \mathrm{~cm}$, sendo que a partir de $80 \mathrm{~cm}$ houve uma estabilização dessa variável (Tabela 10).

Porém, o comprimento das lâminas foliares elevou de forma quadrática com o aumento em altura do dossel: de 22,2 $\mathrm{cm}$ para $66,5 \mathrm{~cm}$, para as folhas expandidas $(\hat{\mathrm{Y}}=-104,311106+2,877570 \mathrm{x}-0,012035$ $\left.\mathrm{x}^{2}, \mathrm{R}^{2}=0,9271, \mathrm{P}=0,002\right)$ e de $29,5 \mathrm{~cm}$ para 57,1 $\mathrm{cm}$, para as folhas em expansão $(\hat{\mathrm{Y}}=-37,491853+$ $\left.1,436966 \mathrm{x}-0,005424 \mathrm{x}^{2}, \mathrm{R}^{2}=0,8831, \mathrm{P}=0,047\right)$, representando, respectivamente, aumento de aproximadamente 3,0 e 1,9 vezes em relação ao comprimento inicial. 
À medida que a densidade volumétrica dos componentes não foi alterada e, considerando-se que a largura da folha também aumenta quando a altura do dossel se eleva (Castro, 2002), a manutenção da densidade volumétrica só pode ter acontecido à custa de menor número de componentes do dossel no mesmo volume, ou seja, folhas, colmos e material senescente. Isso significa que as lâminas foliares, item de maior preferência dos animais, sofrem substancial modificação de acordo com a estrutura da pastagem, tornando-se mais esparsas nas maiores alturas do dossel forrageiro, o que pode dificultar sua captura em pastejo, refletindo em aumento do tempo para formação do bocado, conforme discutido por Carvalho et al. (2001).
Castro (2002) também observou aumento no comprimento de lâminas foliares expandidas e em expansão em milheto manejado segundo alturas variáveis e justificou o fato à alteração na mobilização de nitrogênio das porções senescentes, geradas pelo maior resíduo deixado nas maiores alturas do dossel, para as regiões de crescimento das lâminas foliares, as quais atingiram seu tamanho final mais rápido. Além disso, nas maiores alturas do dossel, as lâminas foliares em expansão permaneceram por maior período no interior das bainhas das folhas expandidas, resultado do maior comprimento do pseudocolmo, o que pode ter levado à redução na taxa de aparecimento de folhas novas e, conseqüentemente, ao aumento no período de alongamento e no tamanho final das folhas (Lemaire \& Chapman, 1996).

Tabela 8 - Densidade volumétrica de lâminas foliares em capim-mombaça (kg de $\mathrm{MS} \mathrm{m}^{-3}$ ), conforme a altura do dossel Table 8 - Leaf blade volumetric density of mombaçagrass $\left(\mathrm{kg} \mathrm{DM} \mathrm{m}^{-3}\right)$ according to sward height

\begin{tabular}{|c|c|c|c|c|c|}
\hline \multirow[t]{2}{*}{$\begin{array}{l}\text { Estrato do dossel }(\mathrm{cm}) \\
\text { Sward strata }(\mathrm{cm})\end{array}$} & \multicolumn{5}{|c|}{$\begin{array}{l}\text { Altura do dossel }(\mathrm{cm}) \\
\text { Sward height }(\mathrm{cm})\end{array}$} \\
\hline & 60 & 80 & 100 & 120 & 140 \\
\hline & & & $\begin{array}{l}\text { le MS } \\
D M n\end{array}$ & & \\
\hline $120-140$ & & & & & 0,14 \\
\hline $100-120$ & & & & 0,10 & 0,32 \\
\hline $80-100$ & & & 0,15 & 0,27 & 0,63 \\
\hline $60-80$ & & 0,05 & 0,47 & 0,52 & 0,90 \\
\hline $40-60$ & 0,10 & 0,36 & 0,69 & 0,82 & 1,09 \\
\hline $20-40$ & 0,31 & 0,73 & 0,63 & 0,65 & 0,57 \\
\hline $0-20$ & 0,22 & 0,31 & 0,22 & 0,23 & 0,12 \\
\hline \multirow[t]{2}{*}{$\mathrm{CV}(\%)$} & & & $\begin{array}{l}\text { ia do } \mathrm{p} \\
\text { ile ave }\end{array}$ & & \\
\hline & & & $\begin{array}{l}\text { le MS } \\
D M n\end{array}$ & & \\
\hline 19,0 & $0,21 b^{*}$ & $0,36 \mathrm{ab}$ & $0,43 \mathrm{a}$ & $0,43 \mathrm{a}$ & $0,54 \mathrm{a}$ \\
\hline
\end{tabular}

* Médias seguidas da mesma letra não diferem significativamente pelo teste Duncan a 5\%.

* Means followed by the same letter do not differ by Duncan test at $5 \%$.

Tabela 9 - Densidade populacional de perfilhos em capim-mombaça (perfilhos.m-2), conforme a altura do dossel Table 9 - Tillers density of mombaçagrass (tillers $\mathrm{m}^{-3}$ ) according to sward height

\begin{tabular}{|c|c|c|c|c|c|}
\hline \multicolumn{5}{|c|}{$\begin{array}{l}\text { Altura do dossel }(\mathrm{cm}) \\
\text { Sward height }(\mathrm{cm})\end{array}$} & \multirow[t]{2}{*}{$\mathrm{CV}(\%)$} \\
\hline 60 & 80 & 100 & 120 & 140 & \\
\hline \multicolumn{6}{|c|}{$\begin{array}{c}\text { Densidade de perfilhos (perfilhos. } \mathrm{m}^{-2} \text { ) } \\
\text { Tiller density (tillers } \mathrm{m}^{-2} \text { ) }\end{array}$} \\
\hline $254 a^{*}$ & $236 a$ & $252 \mathrm{a}$ & $314 \mathrm{a}$ & $264 a$ & 16,1 \\
\hline
\end{tabular}

* Médias seguidas da mesma letra não diferem significativamente pelo teste Duncan a 5\%.

* Means followed by the same letter do not differ by Duncan test at $5 \%$. 
Tabela 10 - Número total de folhas em 100 perfilhos marcados de capim-mombaça, conforme a altura do dossel Table 10 - Total number of leaves on 100 marked tiller of mombaçagrass according to sward height

\begin{tabular}{|c|c|c|c|c|c|c|}
\hline & \multicolumn{5}{|c|}{$\begin{array}{l}\text { Altura do dossel }(\mathrm{cm}) \\
\text { Sward height }(\mathrm{cm})\end{array}$} & \multirow[t]{2}{*}{$\mathrm{CV}(\%)$} \\
\hline & 60 & 80 & 100 & 120 & 140 & \\
\hline $\begin{array}{l}\text { Número total de folhas } \\
\text { Total number of leaves }\end{array}$ & $341 b^{*}$ & $387^{\mathrm{a}}$ & $386 a$ & $364 a b$ & 371ab & 3,34 \\
\hline
\end{tabular}

* Médias seguidas da mesma letra não diferem significativamente pelo teste Duncan a $5 \%$.

* Means followed by the same letter do not differ by Duncan test at $5 \%$.

A probabilidade de desfolhação de folhas individuais, definida como a relação entre o número de lâminas foliares consumidas e o número total de lâminas disponíveis, apresentou redução linear com o aumento em altura do dossel, no tocante às lâminas foliares expandidas (Figura 2). Essa variável apresentou relação negativa com a massa de forragem, como relatado por Pontes (2001), que observou maior probabilidade de desfolhação nas menores alturas de dossel avaliadas. Esta relação direta entre lotação/oferta e a desfolhação de unidades vegetativas individuais está muito bem descrita em Wade (1991), que demonstra o papel preponderante da densidade de animais, mesmo em relação a diferentes métodos de pastejo, na determinação dos padrões temporais da desfolhação.

O comportamento observado para os índices de seletividade passiva e ativa (Figura 3 ) demonstra que os padrões de desfolhação das lâminas foliares expandidas e em expansão alteraram-se, em resposta às diferentes alturas do dossel. Nota-se a forte preferência pelas folhas em expansão, na menor altura, pois a seletividade passiva é maior que 1, preferência que diminui à medida que a altura do dossel aumenta. Como demonstrado pelo índice de seletividade passiva, quando a altura do dossel atinge $85 \mathrm{~cm}$, a relação entre as lâminas foliares desfolhadas em expansão e expandidas reduz-se abaixo do valor de referência 1 , valor que, por definição, significa a inexistência de seletividade. A partir de então, as lâminas foliares expandidas passaram a serem proporcionalmente mais consumidas que as em expansão, demonstrando a preferência passiva manifestada pelos animais, pois, à medida que há incremento na altura do dossel, as lâminas em expansão tornam-se cada vez menos acessíveis em relação às expandidas.

Analisando a relação entre a seletividade ativa e a altura do dossel, verifica-se que, mesmo estando cada

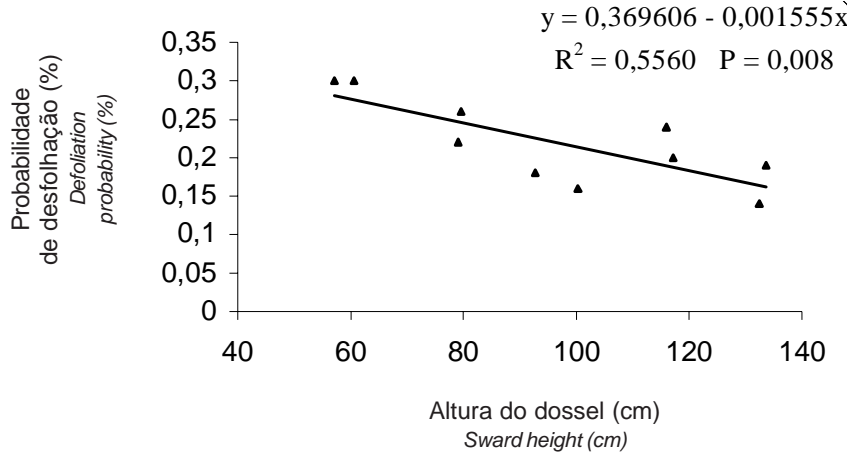

Figura 2 - Probabilidade de desfolhação de lâminas foliares expandidas, referente às alturas de $60,80,100,120$ e $140 \mathrm{~cm}$ do dossel em capimmombaça.

Figure 2 - Defoliation probability of mombaçagrass according to sward heights of $60,80,100,120$ and $140 \mathrm{~cm}$.

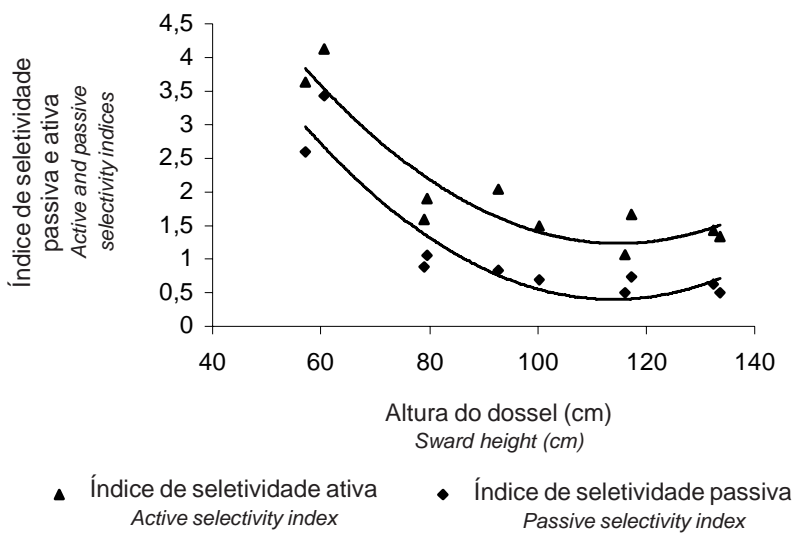

Figura 3 - Índices de seletividade das lâminas foliares, referentes às alturas de 60, 80, 100, 120 e 140 $\mathrm{cm}$ do dossel em capim-mombaça.

Figure 3 - Selectivity index of leaves of mombaçagrass according to sward heights of 60,80,100, 120 and $140 \mathrm{~cm}$. 
vez menos acessíveis, as lâminas foliares em expansão ainda se mantiveram preferidas, uma vez que a curvaresposta posicionou-se sempre acima do valor de referência 1. A partir de $112 \mathrm{~cm}$ de altura do dossel, há tendência de estabilização dos valores de seletividade ativa, ponto a partir do qual o tipo de lâmina foliar escolhida parece ter sido selecionado de maneira muito próxima do casual, mediado pela pronta acessibilidade das mesmas. Esse comportamento dos animais traduziu-se por um pastejo periférico nas touceiras, uma vez que as lâminas foliares externas estariam mais acessíveis aos animais. Em linguagem coloquial, para fácil assimilação, denominou-se este fenômeno de "pastejo tipo mingau", em alusão ao "pastejo tipo espaguete" descrito por Carvalho et al. (2001).

Em pastagem de azevém anual (Lolium multiflorum, L.), Pontes (2001) observou que as lâminas foliares mais jovens foram mais consumidas que as mais velhas, uma vez que as jovens apresentaram crescimento mais vertical e, portanto, estavam mais acessíveis à apreensão pelos animais.

Houve redução na intensidade de desfolhação de lâminas foliares expandidas com o aumento em altura do dossel, a qual variou de 54 a $35 \%$ (Figura 4).

Esse fenômeno pode ser decorrente do maior comprimento e da maior idade dessas folhas, o que as torna, portanto, mais fibrosas (Palhano \& Haddad, 1992) e mais rígidas, condição que, segundo Flores et al. (1993), pode se constituir em

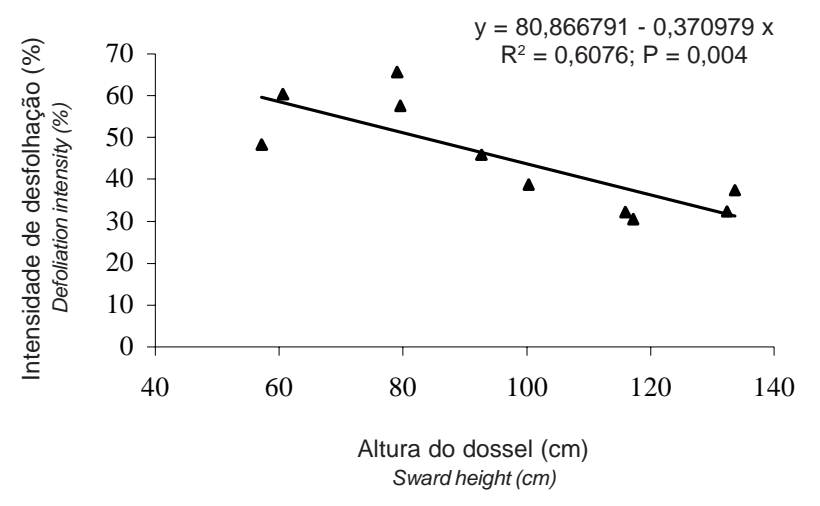

Figura 4 - Intensidade de desfolhação de lâminas foliares expandidas, referentes às alturas de $60,80,100,120$ e $140 \mathrm{~cm}$ do dossel em capimmombaça.

Figure 4 - Defoliation intensity of fully-expanded leaves of mombaçagrass according to sward heights of 60 , $80,100,120$ and $140 \mathrm{~cm}$. efeito negativo à apreensão da forragem e também à proporção de tecido foliar removido em cada bocado (Illius et al., 1995). Além disso, a própria relação entre a massa de lâminas e a taxa de lotação instantânea define, de forma fundamental, a intensidade de remoção das lâminas foliares.

\section{Conclusões}

A densidade volumétrica da forragem de capimmombaça, nas condições avaliadas, não variou com o aumento da altura do dossel forrageiro.

A estrutura do dossel do capim-mombaça influencia o padrão de desfolhação dos animais em pastejo, uma vez que o comprimento das lâminas foliares e sua acessibilidade são marcadamente afetados pela altura do dossel.

A expressão de seletividade pelos animais é modificada pela altura do dossel, à medida que o reduzido acesso às lâminas foliares em expansão induz à opção por lâminas foliares expandidas.

A partir da altura de $112 \mathrm{~cm}$ do dossel, a escolha pelas lâminas foliares em expansão se aproxima da casual, em função de sua acessibilidade e ocorrência.

A intensidade de desfolhação das lâminas foliares é reduzida com o aumento da altura do dossel forrageiro, resultado do maior consumo de lâminas foliares expandidas, mais longas e de mais difícil apreensão.

Com o incremento na altura do dossel, a utilização das touceiras passa a ser periférica, de modo que os animais passam a obter da pastagem dieta de valor nutritivo provavelmente inferior, reflexo da maior ingestão de lâminas foliares expandidas.

\section{Literatura Citada}

BARTHRAM, G.T. Experimental techniques: the HFRO sward stick. Hill Farming Research Organization/Biennial Report, 1985. p.29-30.

CANGIANO, C.A.; GALLI, J.R.; PECE, M.A. et al. Effect of liveweight and pasture height on cattle bite dimensions during progressive defoliation. Australian Journal of Agricultural Research, v.53, p.541-549, 2002.

CARVALHO, P.C.F. A estrutura da pastagem e o comportamento ingestivo de ruminantes em pastejo. In: SIMPÓSIO SOBRE AVALIAÇÃO DE PASTAGENS COM ANIMAIS, 2., 1997, Maringá. Anais... Maringá: Universidade Estadual de Maringá, 1997. p.25-52.

CARVALHO, P.C.F.; PRACHE, S.; DAMASCENO, J.C. O processo de pastejo: desafios da procura e apreensão da forragem pelo herbívoro. In: REUNIÃO ANUAL DA SOCIE- 
DADE BRASILEIRA DE ZOOTECNIA, 36., 1999, Porto Alegre. Anais... Porto Alegre, 1999. p.253-268.

CARVALHO, P.C.F.; MARÇAL, G.K.; RIBEIRO FILHO, H.M.N et al. Importância da estrutura da pastagem na ingestão e seleção de dietas pelo animal em pastejo. In: PEDREIRA, C.G.S.; DA SILVA, S.C. (Eds.) A produção animal na visão dos brasileiros. Piracicaba: Fundação de Estudos Agrários Luiz de Queiroz, 2001b. p.853-871.

CASTRO, C.R.C. Relações planta-animal em pastagem de milheto (Pennisetum americanum (L.) Leeke) manejada em diferentes alturas com ovinos. Porto Alegre: Universidade Federal do Rio Grande do Sul, 2000. Dissertação (Mestrado em Zootecnia) - Universidade Federal do Rio Grande do Sul, 2002.

CHACON, E.; STOBBS, T.H. Influence of progressive defoliation of a grass sward on the eating behaviour of cattle. Australian Journal of Agricultural Research, v.27, p.709-727, 1976.

DURU, M.; DUCROCQ, H.; BOSSUET, L. Herbage volume per animal: a tool for rotational grazing management. Journal of Range Management, v.53, n.4, p.395-402, 2000.

FLORES, E.R.; LACA, E.A.; GRIGGS, T.C. et al. Sward height and vertical morphological differentiation determine cattle bite dimensions. Agronomy Journal, v.85, p.527-532, 1993.

GRIFFITHS, W.M, HODGSON, J.; ARNOLD, G.C. The influence of sward canopy structure on foraging decisions by grazing cattle. I. Regulation of bite depth. Grass and Forage Science, v.58, p.125-137, 2003.

HODGSON, J. Granzing management: science into practice. Longman Group, 1990. 200p.

ILLIUS, A.W.; GORDON, I.J.; MILNE, J.D. et al. Costs and benefits of foraging on grasses varying in canopy structure and resistance to defoliation. Functional Ecology, v.9, p.894-903, 1995.

LEMAIRE, G.; AGNUSDEI, M. Leaf tissue turn-over and efficiency of herbage utilisation. In: SIMPÓSIO INTERNACIONAL SOBRE ECOFISIOLOGIA DA PASTAGEM E ECOlOGIA DO PASTEJO, 1., 1999, Curitiba. Anais... Curitiba: Universidade Federal do Paraná, 1999. p.165-186.

LEMAIRE, G.; CHAPMAN, D. Tissue flows in grazed plants communities. In: HODGSON, J.; ILLIUS A.W. (Eds.) The ecology and management of grazing systems. Wallingford: CAB International, 1996. p.3-36.

MARTINICHEN, D. Efeito da estrutura do capim Mombaça sobre a produção de vacas leiteiras. Curitiba: Universidade Federal do Paraná, 2002. Dissertação (Mestrado em Agronomia, Produção Vegetal) - Universidade Federal do Paraná, 2002.
PALHANO, A.L.; HADDAD, C.M. Exigências nutricionais e valor nutritivo de Cynodon dactylon (L.) Pers. Cv. Coastcross No 1. Pesquisa Agropecuária Brasileira, v.27, n.10, p.14291438, 1992.

PONTES, L.S. Dinâmica do crescimento em pastagens de azevém anual (Lolium multiflorum Lam.) manejadas em diferentes alturas. Porto Alegre: Faculdade de Agronomia, Dissertação (Mestrado em Zootecnia) - Universidade Federal do Rio Grande do Sul, 2001.

PRACHE, S.; GORDON, I.J.; ROOK, A.J. Foraging behaviour and diet selection in domestic herbivores. Annales de Zootechnie, v.48, p.1-11, 1998

PRACHE, S.; PEYRAUD, J. Foraging: behaviour and intake in temperate cultivated grassland. In: INTERNATIONAL GRASSLAND CONGRESS, 19., 2001, São Pedro. Proceedings... São Pedro, 2001. p.309-319.

SANTOS, P.M. Estudo de algumas características agronômicas de Panicum maximum (Jacq.) cvs. Tanzânia e Mombaça para estabelecer seu manejo. Piracicaba: Escola Superior de Agricultura Luiz de Queiroz, Dissertação (Mestrado em Agronomia, Ciência Animal e Pastagens) - Escola Superior de Agricultura Luiz de Queiroz, 1997.

SBRISSIA, A.F.; DA SILVA, S.C. O ecossistema de pastagens e a produção animal. In: PEDREIRA, C.G.S.; DA SILVA, S.C. (Eds.) A produção animal na visão dos brasileiros. Piracicaba: Fundação de Estudos Agrários Luiz de Queiroz, 2001. p.731-754.

UEBELE, M.C. Padrões demográficos de perfilhamento e produção de forragem em pastos de capim-mombaça submetidos a regimes de lotação intermitente. Piracicaba: Escola Superior de Agricultura Luiz de Queiroz, Dissertação (Mestrado em Agronomia, Ciência Animal e Pastagens) Escola Superior de Agricultura Luiz de Queiroz, 2002.

WADE, M.H. Factors affecting the availability of vegetative Lolium perenne to grazing dairy cows with special reference to sward characteristics, stocking rate and grazing method. St-Gilles: Universidade de Rennes, 1991. Tese (Doutorado em Ciências Biológicas) - Universidade de Rennes, 1991.

Recebido em: 18/02/03 Aceito em: 08/06/05 